\title{
Hidden expectations: scaffolding subject specialists' genre knowledge of the assignments they set
}

\author{
Lisa McGrath ${ }^{1} \cdot$ Raffaella Negretti $^{2} \cdot$ Karen Nicholls $^{1}$
}

Published online: 2 March 2019

(C) The Author(s) 2019

\begin{abstract}
Subject specialists' knowledge of academic and disciplinary literacy is often tacit. We tackle the issue of how to elicit subject specialists' tacit knowledge in order to develop their pedagogical practices and enable them to communicate this knowledge to students. Drawing on theories of genre and metacognition, a professional development activity was designed and delivered. Our aims were to (1) build participants' genre knowledge and (2) scaffold metacognitive awareness of how genre knowledge can enhance their pedagogical practices. The findings reveal that participants built a genre-based understanding of academic literacy and that the tasks provided them with an accessible framework to articulate and reflect upon their knowledge of disciplinary literacy. Participants gained metacognitive awareness of misalignments between what they teach and what they expect from students, their assumptions about students' prior learning and genrebased strategies to adapt their practice to students' needs. Our approach provides a theoretically grounded professional development tool for the HE sector.
\end{abstract}

Keywords Academic literacy $\cdot$ Disciplinary literacy $\cdot$ Genre $\cdot$ Metacognition $\cdot$ Professional development

\section{Introduction}

This is something that my colleagues and I often talk about - why don't students write well (...) but other than sending them to our Writing Centre we rarely do anything about this. (P10)

Lisa McGrath

1.mcgrath@shu.ac.uk

1 Sheffield Institute of Education, Sheffield Hallam University, Arundel Building, Howard Street, Sheffield S1 1WB, UK

2 Department of Communication and Learning in Science, Division for Language and Communication, Chalmers University of Technology, Gothenburg, Sweden 
This quote from our data encapsulates the pressing issue that we tackle in this paper: the role of subject specialists in students' academic literacy development.

Although literacy is integral to academic success (Sala-Bubaré and Castelló 2017), the expectation that students arrive at university equipped with the necessary skills, or that these skills will develop implicitly, still persists (Dysthe 2002). Some students will indeed familiarise themselves over time with the discourses of their disciplines; nonetheless, rarely does subject teaching explicitly facilitate enculturation, the 'initiation into the shared conventions of discourse communities that govern how members speak and write' (Prior 1998, p. 12). The situatedness of academic discourse (Hyland 2004) means that academic literacy development must be tied to disciplinary literacy (Paxton and Frith 2014) - the 'knowledge and abilities possessed by those who create, communicate, and use knowledge within disciplines' (Shanahan and Shanahan 2012, p. 8) - and foregrounds the role of subject specialists in facilitating or expediting literacy development.

Unfortunately, this development - in English for Academic Purposes (EAP), but also in writing and skills centres working with other academic languages - has historically been somewhat detached from disciplines. Johns (1997) highlighted this decontextualisation, arguing that academic literacy development should not be the sole purview of EAP specialists, encouraging 'all faculty to take responsibility for student literacy growth' ( $\mathrm{p}$. 71). This view has been echoed by Elton (2010) and Wingate (2016). Percy (2014) goes further by advocating the 're-integration' of staff responsible for the professional development of lecturers and those responsible for the development of student academic literacy in order to 'promote the development of language and learning simultaneously' (p. 1203). Currently, however, subject modules remain primarily occupied with content knowledge; learning outcomes are formulated in terms of disciplinary content acquisition, with little attention to the literacy development required for communication of that knowledge. A shift is required in subject specialists' perceptions about what academic literacy is and who is responsible for its development.

Several barriers obstaculate subject specialists' deeper engagement with academic literacy development. Few have expertise in teaching academic literacy (Jenkins and Wingate 2015), and interactions between subject and literacy specialists sometimes lack a 'constructive collaboration between equals' (Elton 2010, p. 151). Additionally, and germane to our purposes, subject specialists may struggle to articulate their values and expectations (Dysthe 2002), since disciplinary literacy often constitutes tacit or 'hidden' knowledge (Haggis 2006, p. 530). Tacit knowledge, the idea that 'we know more than we can tell' (Polanyi 1966, p. 4), is often acquired by implicit learning and poses two challenges: awareness and representation (Eraut 2000). Awareness of having knowledge does not mean that the knower can explain the process by which that knowledge was gained, and representation poses the problem of how tacit knowledge can be elicited and communicated. In an academic literacy context, the result is a lack of transparency in what is expected of students in their assignments (Lillis and Turner 2001), or-as our starting quote implies - a lack of tools to address the problem.

It is this problem of subject specialists' tacit knowledge of academic and disciplinary literacy that we address. Unlike the vast majority of HE research on academic literacy, which deals with theories underpinning practice (e.g. Lea and Street 2006; McGrath and Kaufhold 2016; Swales 1990), student learning (e.g. Cheng 2018; Johns 2008; Negretti 2017), and the training of EAP lecturers (e.g. Lee 2013; Tardy et al. 2018), our focus is the subject specialist. Our study adopts an inter-disciplinary approach, drawing on theories of genre (Tardy 2009; 
Swales 1990) and metacognition (Flavell 1979) to construct a scaffolded professional development activity for subject specialists with two aims: building genre knowledge, and scaffolding metacognitive awareness of how genre knowledge has a bearing on pedagogical practices. By combining theories of genre and metacognition in task development (Negretti and McGrath 2018), we are able to elicit subject specialists' tacit knowledge and support them in gaining awareness of their own expectations and misalignments in their practice. The findings show that genre theory can help subject specialists build an understanding of academic literacy, while metacognitive training provides an opportunity to articulate and reflect upon their tacit disciplinary knowledge and practice, ultimately enabling them to apply their insights to courses. The result is an innovative tool, grounded in metacognitive training heuristics, which can be used across the HE sector.

\section{Theoretical framework}

\section{Genre knowledge}

We hold that the development of academic literacy entails the development of genre knowledge (e.g. Tardy 2009). Our use of 'genre' draws on socio-rhetorical understandings from applied linguistics and rhetorical studies. These fields have been influential in HE research and pedagogy in academic literacy, conceptualising genres as repeated social actions (e.g. Miller 1984; Swales 1990), 'channels of communication' that regulate discourse among specific groups (Tardy 2009, p. 13). This means that 'learning to use genres requires more than learning text types and forms; it requires learning the social contexts, actions and goals that give genres their meaning' (Tardy 2009, p. 12). Thus, we align academic literacy with genre knowledge, which comprises knowledge of the textual manifestations of the genre, as well as 'less visible knowledge' (Tardy 2009, p. 19) such as community values, ideologies and epistemology (cf. Berkenkotter and Huckin 1995). Tardy proposes a theoretical framework and definition of genre knowledge which comprises four dimensions (see Fig. 1):

Formal knowledge pertains to the lexicogrammar and structure, the conventionalised oral/ textual form of the genre. Rhetorical knowledge refers to the intended purpose of the genre,

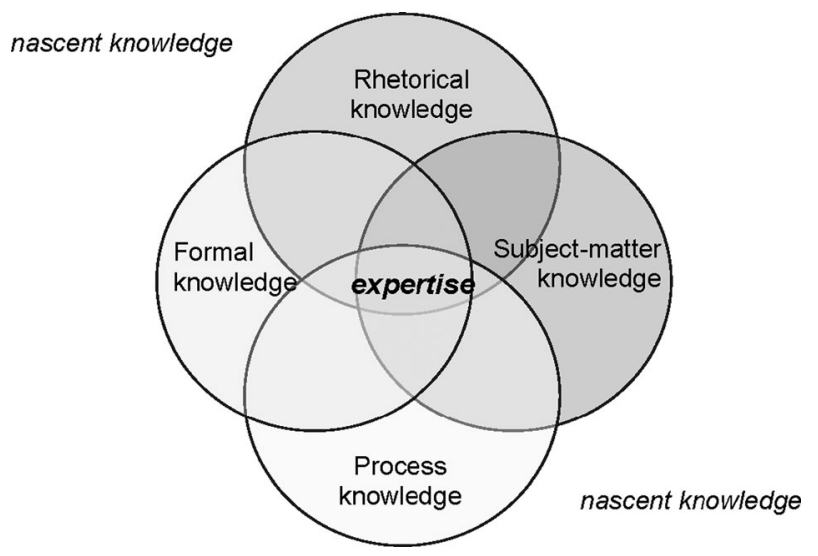

Fig. 1 The development of genre knowledge. From Building Genre Knowledge by Christine Tardy (Parlor Press Tardy 2009). Used with permission 
author positionality and audience awareness, disciplinary values and communities. Process knowledge covers the 'procedural practices' involved in producing the genre. This includes the stages required to complete the communicative act (e.g. produce an essay), such as literature searches and composition. Subject-matter knowledge pertains to the content learned in the disciplines (i.e. the maths in mathematics). These four dimensions are a heuristic and have considerable overlap. Novice writers may separate these facets in their composing processes, but as expertise in the genre develops, they become integrated (Tardy 2009, p. 21).

\section{Metacognition}

Subject specialists possess tacit genre knowledge: they are able to perform the various genres used by their disciplinary community. This knowledge needs to become explicit and metacognitive if they are to reflect on how it informs teaching. Space precludes a detailed account of metacognition theory, so a schematic overview is provided in Fig. 2.

Metacognition was proposed by Flavell (1979) to theorise the ability to reflect on what we know and how we use this knowledge, a key dimension of learning. As Fig. 2 shows, metacognition is multifaceted and includes a variety of components. Metacognitive awareness (or knowledge) and metacognitive regulation (or skills) are the two most widely recognised. Metacognition is developed through metacognitive experiences (Dinsmore, Alexander and McLoughlin Dinsmore et al. 2008) that make us reflect on our skills, knowledge, goals and/or the accuracy of our self-evaluations.

Our focus is metacognitive awareness. Metacognitive awareness precedes metacognitive monitoring and control (see Fig. 2), and means understanding what we know, our own cognitive processes and strategies, how we use this knowledge in what we do, and how we adapt this knowledge to situations (Schraw and Dennison 1994). Metacognitive awareness is triggered 'when something changes, when something is unexpected, or, when something goes

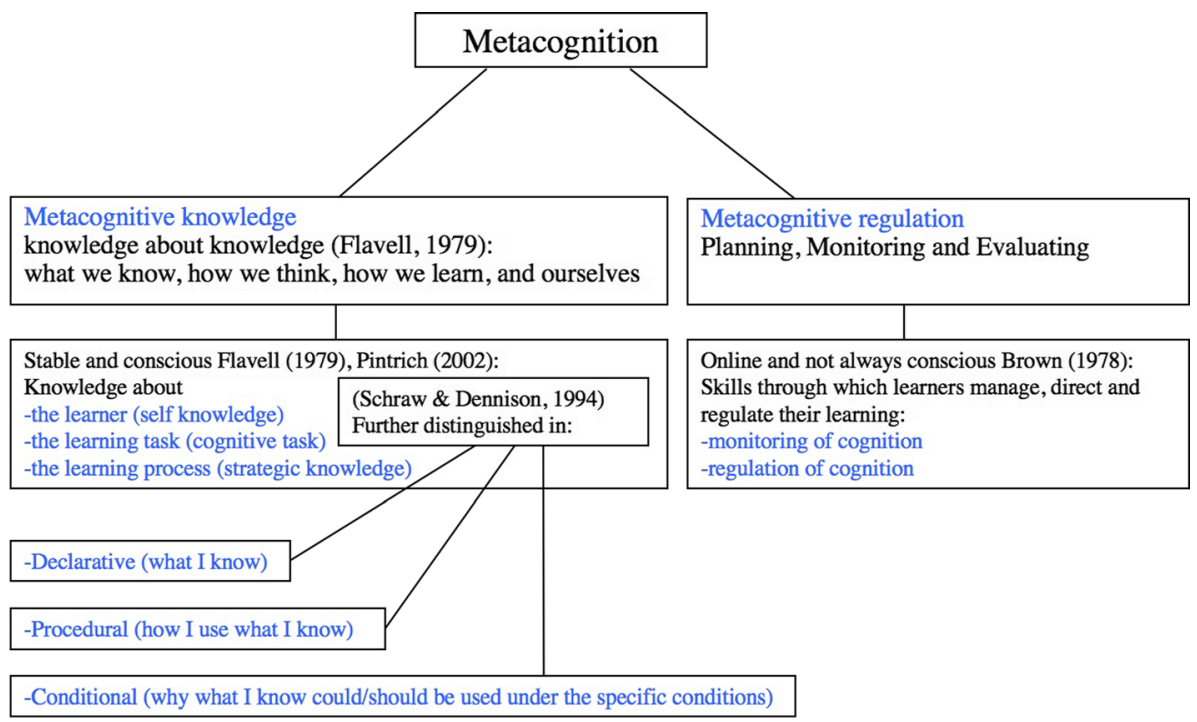

Metacognition theory: a schematic summary based on Flavell (1979), Brown (1978), Schraw \& Dennison (1994), Pintrich (2002)

Fig. 2 A schematic overview of metacognition (Negretti and McGrath 2018). Used with permission 
wrong' (Metcalfe and Schwartz 2016, p. 408), for instance, when we realise that we do not actually remember or understand something we studied. These experiences push us to reflect on our cognition and realise what we need to improve, or at least lead to a more accurate assessment of our knowledge. Our tasks are designed to be that trigger. Although metacognitive awareness can occur spontaneously, its development needs to be explicitly trained to be effective. For example, learners can be guided to identify what is known and not known at the start of a task, and learner-generated questions can be elicited (for examples of metacognitive training, see, e.g. Hargrove and Nietfeld 2015; Serra and Metcalfe 2009; van de Kamp et al. 2016). In what follows, we elaborate on these considerations in relation to the intervention design.

\section{Methodology}

\section{Setting and participants}

The study was conducted at a UK university, with 13 early career lecturers taking a postgraduate certificate in learning and teaching in HE, and their tutor (P11). Informed consent was obtained. The range of participants' specialisms is reported in Table 1, along with the genres (assignments), the participants selected for the activity. The genre names given by the participants reflect their understanding of the assignment; however, these names do not necessarily reflect prototypical descriptions of the genre (see Nesi and Gardner 2012 on the problem of genre naming).

\section{Task design}

The first author was invited to develop a session addressing academic literacy for subject specialists, delivered the session, recruited participants and collected data. This active researcher role enabled insight into the dynamics of the setting and a rapport with the participants

Table 1 Participants' field and genre

\begin{tabular}{lll}
\hline Participant & Field & Genre \\
\hline P1 & Management & Essay \\
P2 & Aerospace engineering & Report \\
P3 & French & Coursework writing assignment \\
P4 & Computer science & Coursework \\
P5 & Human geography & Essay \\
P6 & Media studies & Blog post \\
P7 & Law & Critical essay \\
P8 & Law & Problem question \\
P9 & Education & Creative viva \\
P10 & Literature & Common place book \\
P11 & Higher education & Critical essay \\
P12 incomplete data-withdrawn & \\
P13 & Criminology & Group presentation \\
P14 & Games design & Reflective report \\
P15 & Biology & Course work essay \\
P16 incomplete data-withdrawn & \\
\hline
\end{tabular}


(e.g. Crookes 1993). The session lasted $2 \mathrm{~h}$. In the first hour, the first author introduced Tardy's (2009) four facets of genre knowledge to promote an understanding of their significance in relation to students' production of assignments, and modelled task 1 (Fig. 3), an analysis of an assignment genre. In the second hour, participants worked through tasks 2 and 3 (Fig. 3) using the module guide, assignment brief and a sample of the assignment they wished to consider.

The tasks were developed to metacognitively scaffold subject specialists' knowledge of the formal, rhetorical and process aspects of genres used in their pedagogical practice, to raise and elicit awareness of participants' tacit expectations in relation to the assignments they set and to elicit an awareness of how academic literacy development is embedded in participants' courses (or not). Similar to other metacognition training interventions (van de Kamp et al. 2016), our approach adopted a series of steps for the explicit instruction of metacognitive awareness. This type of approach is based on Nelson and Naren's (Nelson and Narens 1990) theoretical model of the learning loop: as new knowledge is developed, this knowledge is monitored at the metacognitive level, where it is evaluated, connected to previous knowledge and used to make decisions about further use of this knowledge. Thus, individual and collaborative activities facilitate both the construction of new knowledge and metacognitive awareness of how to use

Task 1: Mapping the genre knowledge

Using the assignment you brought to the session as a stimulus, think about the genre knowledge the student needed in order to successfully write this genre (content, rhetorical, formal, process). Make notes next to the relevant circle. Remember, the circle diagram is a heuristic, and in some cases, the knowledge may span multiple genre knowledge areas (20 mins).

\section{A reminder of the categories (Tardy, 2009)}

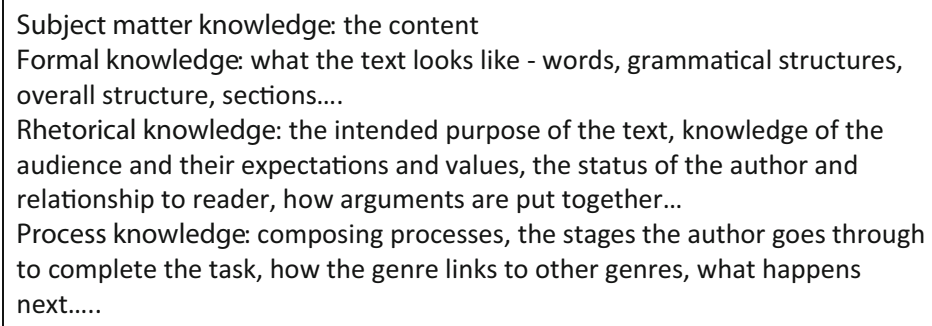

Task 2: Evaluating

Now look at your module handbook. To what extent are the different aspects of genre knowledge you have noted on the diagram taught/developed on the module? What knowledge is assumed to be in place? What is the balance between attention to content knowledge and the rhetorical, formal and process aspects of genre knowledge on the module? Discuss your observations with a partner (15 mins).

Task 3

Reflect on the tasks and discussions this session. What insights have you gained? What do these insights mean for your teaching and module leading practice? How might you adapt your practice? Why? Please make some notes below (20 minutes).

Fig. 3 Task handout 
this new knowledge to monitor and control one's performance. In our approach, we devised three steps: eliciting tacit knowledge through Tardy's framework, promoting the integration of this knowledge into the participants' experience and helping participants' conceptualise and evaluate this knowledge for future use.

Task 1 aimed to elicit tacit knowledge using Tardy's model as a prompt, triggering metacognitive awareness of how literacy development is (or is not) embedded in participants' modules. This step loosely corresponds to van de Kamp et al.'s (2016) metacognitive intervention steps 1-2: activating prior knowledge and constructing new cognitive and metacognitive knowledge.

Task 2 was a discussion to further situate the new knowledge derived from task 1 into the participants' own context, corresponding to van de Kamp et al.'s tasks 3, 4 and 9 (promoting integration, reflections and evaluation of new knowledge into the learners' own experience). This stage aimed to lead participants towards the construction of higher-order knowledge about academic literacy and metacognitive awareness about how to conceptualise disciplinary literacy in their fields.

Task 3 corresponds to the final two steps in van de Kamp et al.'s (2016) intervention, which focus on constructing higher-order knowledge: integrating newly acquired knowledge, conceptualising beyond one's own practice or experience and supporting reflection and evaluation of what this conceptual knowledge means for one's practice. This step in metacognitive knowledge training, 'summarisation' (Serra and Metcalfe 2009), is crucial for connecting metacognitive knowledge to monitoring and regulation: how can this knowledge be used? How can I use this new way of thinking about literacy to monitor and regulate my thinking about my practice?

\section{Analysis}

Data were collected from the participants' responses to task 1 and task 3 . We took an 'inductive stance' (Yin 2016); although our study was based on established theories, those theories did not drive our coding. In the initial stages, we used analytic memos and annotations to allow the data to suggest possible themes (Yin 2016, p. 132). All three authors conducted the first analysis of the data set individually, documenting 'reflections and thinking processes' (Miles et al. 2014, p. 95).

Individual analysis was followed by a comparison of our annotated data and memos. Discussion around observed interpretations and patterns led to a preliminary set of codes. Integration of our individual codes was relatively unproblematic, as our initial annotations were strikingly similar. We provide the following data extract by way of example:

This model has highlighted that a lot of what is expected from our students is NOT taught and as a department we assume they come to university with a skillset that includes being able to write academically. We assume the school system (A Levels) teaches them the appropriate knowledge information \& skills. (P6)

The first author annotated 'discrepancy between teacher expectations and what students know', while the second author noted 'meta-awareness of the discrepancy between expectations and what they do/teach in their courses' and 'meta-awareness of own assumptions about students' skills/needs (and their unfoundedness)'. Our collaborative discussion necessitated a return to the data, a cyclical pattern typical of qualitative research (Miles et al. 2014, p. 95). 
Next, we connected our codes to the theories in which our study is rooted, 'reassembling' the data (Yin 2016). For task 1, we super-imposed the four facets of genre knowledge onto the data coded through our inductively derived themes. This allowed us to group our coded data, see how the participants had interpreted the different facets and individuate data-derived themes within each of those facets. For task 3, we referred to the theory of metacognition, which enabled us to group the data excerpts according to types of metacognitive awareness suggested by the participant's comments (our inductive codes, see the 'Scaffolding metacognitive awareness: responses to Task 3' section). This phase was carried out collaboratively and verified against the data set.

Finally, we moved from analysis to interpretation to create a narrative (Yin 2016, p. 187). This interpretation at times required us to problematize our coded data and partially recompile our set of quotes in the manuscript to ensure more accuracy. This reflexive, collaborative analytic process and repeated verification of coding and interpretation were crucial to establish systematicity and trustworthiness in our qualitative approach (Lincoln and Guba 1985).

\section{Results}

\section{Responses to task 1}

Task 1 required participants to annotate Tardy's genre knowledge model in relation to their selected assignment. The model elicited a range of responses. Some participants expanded on various facets of genre knowledge and showed how these facets interrelate (e.g. P14, Fig. 4), while others were more brief.

In the following sections, we report on the facets of genre knowledge that the participants described. We do not elaborate on content knowledge, as this was expected to be less tacit.

\section{Rhetorical knowledge}

Most participants did not elaborate on rhetorical knowledge at length. For instance, P3 stated 'accuracy, targeted audience (me)', and P6 described the audience of a blog post as 'expert audience and public'. Where participants did elaborate, they foregrounded challenges posed by the assignments for students in terms of audience and purpose. P14 discussed two assignments on the same games design module: first, a project aimed at a 'professional/lay audience' and second, a report aimed at 'staff/academics', requiring students to tailor their writing to an academic and popular audience within one module. Participants also noted that assignments sometimes asked the students to assume academic and/or professional roles that they had not yet experienced, particularly in the more professionally oriented disciplines. For example, P8's assignment required students to place themselves in the role of a solicitor advising a client in a genre named 'problem question', and P1 (management essay) expected students to provide professional guidance: 'suggestion provided as consultant'.

P7 expanded on audience expectations: 'our values - values of criminal theory, demonstrating nuance, demonstrating controversial elements', which he ties to the purpose of the essay: 'knowing the purpose i.e. to make a critical argument'. Similarly, P13 mentioned values and expectations ('criminology values') but without specifying what they are or how they 


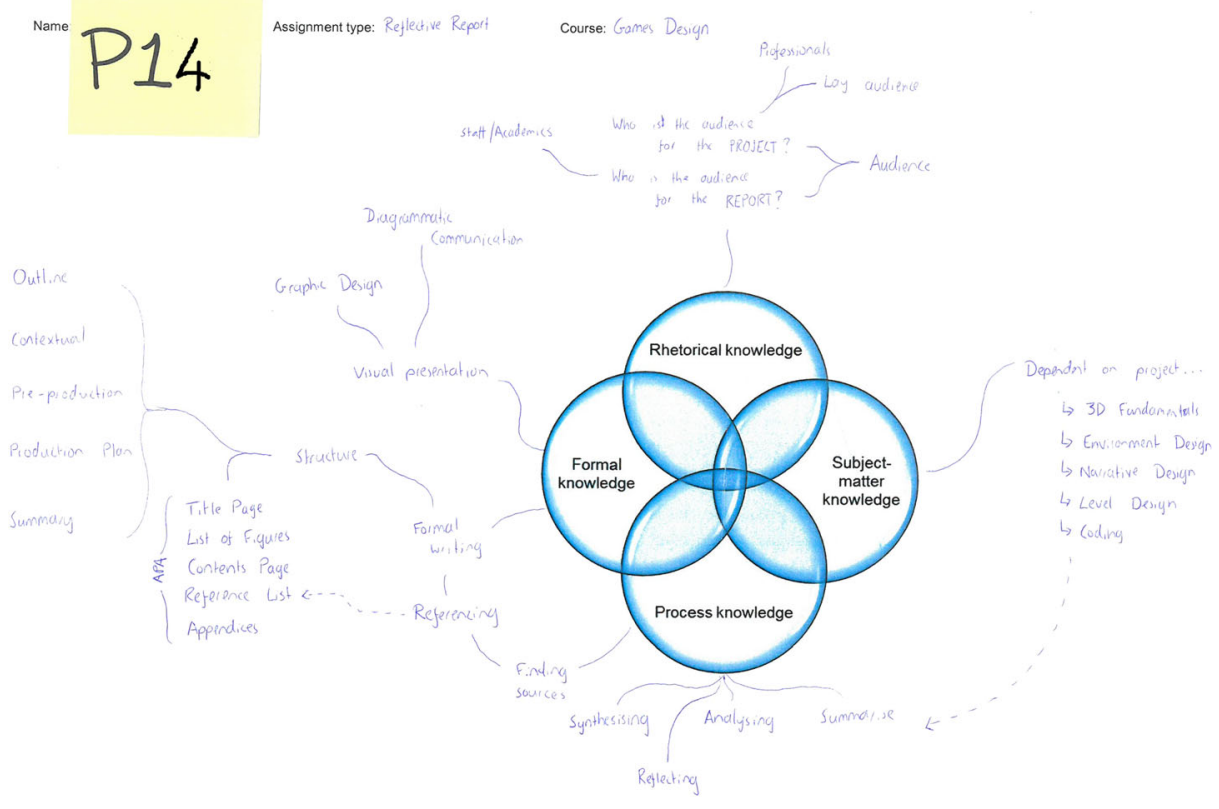

Tardy, C. (2009). Building genre knowledge. West Lafayette: Parlor Press.

Fig. 4 Task 1, P14

connect to the assignment (a group presentation). P15 expanded more: 'values of community, why we want to improve health'. Finally, P9 considered values that the students were expected to exhibit in their author roles: 'creativity, criticality, reflection'. These comments suggest that the task challenged participants to articulate their tacit rhetorical knowledge - expectations, values - and to recognise the challenge this poses for students.

Another rhetorical dimension was the purpose of the genre. An extended annotation came from P11, who underscored the complexity of the assignment: 'challenge own perspectives, different perspectives, critique dominant discourse, critique established ideas and theories, value of reflection, owning own development'. Rhetorical knowledge (purpose) and process knowledge were also sometimes combined. For example, P5 (essay) noted 'critical analysis/ thinking, acknowledging counter arguments, critical analytical writing, developing an argument, reflectivity [sic]'.

Thus, 'rhetorical knowledge' elicited an awareness of (tacit) audience expectations, values, desirable author attributes and implied purposes of the participants' assignments. This task also seemed to promote recognition of the difficulty inherent in conveying this specific genre knowledge to students and the complexity of the assignments set.

\section{Process knowledge}

Descriptions of processes were detailed, comprising steps that included behavioural strategies (e.g. going to the library) and cognitive strategies (e.g. synthesising), some of which- 
analysing, evaluating and creating - are advanced on the revised Bloom's taxonomy of cognitive complexity (Krathwohl 2002).

All the participants mentioned reading or retrieving relevant information as a starting point for the assignments, to refresh key concepts or identify relevant literature. The range of texts was noted, for example P1 (management) mentioned 'reading news around the case as well as academic journals' and P2 (engineering) listed 'research/read textbooks, journal articles, conference papers, online sources'. This initial step implied using selection strategies or critical reading skills. For instance, P13 (criminology) noted 'research methods (optional), finding literature, choosing a focus', and P2 (engineering) listed 'reading news around the case as well as academic journals, finding relevant material from academic publications available'. Process descriptions included discipline-specific, technical strategies; for instance, P2 (engineering, report) mentions that the assignment requires students to 'simulate systems/results/complete lab'. Likewise, P4 (computer science, coursework) mentions 'using the library and Dr. Google', and more technical strategies 'use right tools for coding, use version control'. Discipline-specific non-technical strategies included 'write a reflective account (diary, photo elicitation)' (P5, human geography, essay); 'research law of succession and understanding detail, set out the rules for a valid will' (P8, law, problem question); 'chronology of events, educational identity construction (reflective story)' (P9, education, creative viva). Overall, these comments evince the overlap between process and purpose, signalling the integration of facets of genre knowledge that assignments demand from the students.

The behavioural strategies were connected, often in sequence, to cognitive strategies. Some of these were also discipline specific and complex (cf. Bloom's taxonomy). This 'doing to thinking' sequence is illustrated by P11's comment (higher education, critical essay): 'Using library catalogue, google scholar, summarise, synthesise, criticise, conclude, link to own specialism'. The complexity of cognitive strategies required by the assignments is evident in most of the process descriptions. P9 (education, creative viva) detailed the process she expected students to undertake: 'discussion of chosen theory; synthesis of story and theory; critique and discussion'. Similarly, synthesis segued into critique and creation of an original argument in P5's assignment (human geography, essay): 'understanding arguments (summarise), analysing arguments, developing your own argument'. P7 (law, critical essay) also emphasised the sequential nature of the process, which entails sophisticated and discipline-specific steps: 'engaging with critical literature, knowing the task, analysing, synthesising, writing an argument, persuading, specific criterion they had to meet: what's the response? Does it work?' Finally, P8's assignment (law, problem question) required 'critical analysis of the scenario and apply the law to the facts and determine the outcome'.

To summarise, process knowledge elicited multi-step descriptions which at times required the application of the highest level of cognitive complexity skills to a very discipline-specific problem. Although common themes cut across the participants' comments - e.g. reading and finding relevant information - most processes became tied to disciplinary literacy, especially when they required students to demonstrate creativity and originality.

\section{Formal knowledge}

Here, the participants invoked different types of literacy: academic, disciplinary, multi-modal and digital. As was the case with process knowledge, the participants' comments showed 
overlaps among formal aspects (sentence, register, punctuation, text structure), disciplinaryrelevant content and rhetoric.

Lexico-grammatical features noted included concision, sentence complexity, pronoun usage and terminology, reflecting differences in disciplinary expectations and/or genre conventions. For example, P2 (aerospace engineering report) expected 'short, simple sentences' and 'past tense third person sentences (in the next stage the system was simulated under transcient [sic] conditions)'. In contrast, P11 (higher education critical essay) noted 'complex sentences, structure, tentative language (think, possibly, could, suggest)' and 'reflective language, use of first person'. Most participants also mentioned reference styles. These comments reveal language features that are tied to prototypical disciplinary genre conventions, invoking both academic and disciplinary literacy.

This situatedness was also apparent in the many mentions of disciplinary terminology/ concepts, such as 'professional language in business' (P1) and 'Engineering terminology' (P2). Other comments seemed to merge content (concepts), genre-specific rhetorical moves and multi-modal or digital dimensions with formal features. In terms of multimodal literacy, P14 (games design reflective report) described formal features as comprising 'diagrammatic communication, graphic design, visual presentation, outline, contextual, pre-production, production' and P5 (human geography essay) noted 'structure - reflection (+evidence, e.g. photos'). P6 (media studies blog post) invoked digital literacy 'embedded hyperlinks and citations', as did P14 'use computer memory effectively, time-consumption measure, friendly user interface'. Some of the formal features described referred to rhetorical knowledge, such as P10's comment about 'knowing how to pitch the assignment' or P8's talk of a 'conclusion to draw the advice together, requires introduction setting out parties, law and the issues and facts'.

This indicates that the participants struggled to articulate formal knowledge, and interwove formal features with key concepts, rhetorical aspects and processes and purposes. In other words, the formal features seemed blurred in these depictions, suggesting that formal expectations constitute tacit knowledge. This fuzziness is encapsulated by P10's description of an 'informal artifact but still requires formality, knowing how to pitch the assignment. Find quotations, informal register, but still need bibliography, formal structure' (our emphasis).

To summarise 'Responses to task 1', task 1 began to focus the participants on aspects of genre knowledge outside of content knowledge, helping to build an appreciation of assignments as multifaceted, disciplinary and genre specific. The elicitation was a first step towards metacognitive awareness as participants brought to the surface and articulated their implicit expectations and reflected on their own practice in connection to Tardy's model. The participants' discussion of the model in groups, and especially their responses reported in task 3 , suggest that task 1 triggered an 'aha' moment for many, i.e. a metacognitive experience where they could reflect on, problematize and reframe their perceptions of their own pedagogy.

\section{Scaffolding metacognitive awareness: responses to task 3}

In task 3, three main themes emerged: (1) metacognitive awareness of the participants' own expectations of the module/assignment and the discrepancy between what they teach and expected student outcomes, (2) metacognitive awareness of their own assumptions about students' current skills and prior learning and (3) metacognitive awareness of how Tardy's model could be used to adapt their module/teaching to students' needs. 
Participants adapted to the metalanguage introduced for discussing genre knowledge and incorporated the concepts into their responses. They used the concepts to structure their thinking and situate their observations in relation to genre knowledge and within their own practice, as shown in what follows.

\section{Metacognitive awareness of the participants' own expectations of the module/ assignment and the discrepancies between what they teach and expected student outcomes}

Many participants discerned a gap between their expectations and their practice. For instance, P7 noticed that she herself lacks clarity on how she expects the assignment to be completed, which contrasts with her clarity about the final product:

I really enjoyed doing this task. ... Maybe I am less clear on how I want them to complete the task/the formal knowledge than I am the outcome of what I expect to see.

So this is an interesting reflection for me. (P7)

Closely linked was an awareness of a misalignment between what is taught and the outcome for students. For instance, P3 noticed a gap between teaching and assessment, realising that some aspects of genre knowledge are neglected in her teaching, even though she sees the importance of developing all four facets:

I realised [...] we did not/do not cover all the areas of knowledge, and I think it is important. For example, the process knowledge, we expect them to read outside of the class or make a draft but we do not ask them or we do not leave enough space for their own reflection. However, in the assessment they need to do that. (P3)

P2 echoed this lack of alignment between teaching and assessment by commenting that, through the tasks, he realised his own expectations did not match what students were told:

Task 2 highlighted the huge gap between the instructions given to the students and our expectations for the module's assessment (P2)

Many of the participants observed a gap between their teaching and their expectations about learning outcomes. The extract below suggests that P1 gained metacognitive awareness about his 'responsibility' as a lecturer and of the role of language in content knowledge development:

I as an academic did not know that we are responsible to emphasize on [sic] all the genres while teaching. My students are all with engineering background and lack so many aspects of the model, for instance the formal knowledge is so evidently poor and needs more concentration. (P1)

There were other realisations of misalignment. For example, P9 noticed her own assumption that formal and rhetorical knowledge would be conveyed implicitly through her teaching or were expected to be in place through students' prior learning (this point is developed further in the next section):

It also made me very aware that we don't not [sic] explicitly cover formal knowledge... particularly based on the assumption that at level 6 we assume students should know most of this knowledge, but also because, like rhetorical knowledge, I sometimes assume that it is implicit the way that I teach and activities I set. (P9) 
P15 noted a focus on subject-matter knowledge in her practice, which she relates to her discipline (biology). She then evaluated this practice, noticing a mismatch between what is taught and how the students are assessed:

I have realised that due to the nature of my subject topic, I only give the students subjectmatter knowledge but nothing else. We rely on other part [sic] of our department to try and deliver some of this i.e. tutorials for improving process knowledge and formal knowledge. However in our assessment of the coursework, we give marks for all the other aspects which now seems a bit unfair. (P15)

Finally, P13 reflected on the mismatch between her expectations and the students' expectations of an academic assignment, a potential conflict. Specifically, she reflects on challenges students face when shifting from an academic context to a professional context ('a work product'):

Students may expect that university involves essays and exams. To ask them to produce a work product utilising their discipline knowledge may leave them wondering why it's relevant to 'university'. This could cause them undue stress because they may be feeling that they are just getting used to the university formal and rhetorical knowledge, before being asked to adjust. (P13)

This section highlights the participants' metacognitive awareness of the potential discrepancies between their (often implicit) expectations and what they teach or what the students are asked to produce. In the next section, we show that this misalignment is connected to a mismatch between what subject specialists think students know, and what is actually required in the participants' assignments/modules.

\section{Metacognitive awareness of participants' own assumptions about students' current skills and prior learning}

P10 illustrates gaining metacognitive awareness of his assumptions about students' prior knowledge, which is implicitly required by the assignment set:

When setting assignments there is much assumed knowledge; I hadn't noticed how much I assume that students will know outside of subject matter knowledge. (P10)

P13 provided a more detailed account of her assumptions, touching on rhetorical knowledge. Students are expected to give a 'professional' presentation, and she realised that those who have work experience may have acquired rhetorical genre knowledge that others lack:

I have realised that there is some element of assumed knowledge for the assessment, particularly in relation to professional standards and values. Expecting students to deliver a professional standard presentation without ever working in the sector is very difficult. Although they have some earlier knowledge of working with external organisations on their degree, it is clear to me now that students who may engage in volunteering or part-time work may have an advantage over those who don't in terms of understanding what's expected in a working environment. (P13)

The following extract from P11 indicates a gain in metacognitive awareness about her own high expectations, and a realisation that her assumption that students have adequate prior knowledge may be unreasonable: 
Biggest insight gained is the amount of rhetorical knowledge that I expect them to have about what we (and perhaps, to an extent, I - which is something I need to be aware of) expect and value in educational writing - and it's not likely they would know all of this. (P11)

Finally, P7's reflections index metacognitive awareness of her lack of clarity about whether students' prior knowledge can be assumed. She posed a series of rhetorical questions that show how she used this metacognitive awareness to problematize her practice and that of her colleagues:

I think there are expectations established over their ability to use the library and reference at this stage $[\ldots]$ how to structure the work (it is a fairly standard essay format with clear sections outlined for them). However, some still struggle at this stage (and also at level 6). [...]I am still unclear what we should be expecting from them at level 5 and 6, i.e. if we know they have learnt referencing at level 4 but are not doing it where does the responsibility fall to teach them? Can we expect them to know certain things or should we be building in the teaching across the 4 knowledge facets in every module? Is this model more useful when we think at a whole course level (i.e. across the full 3 years) to see how each module contributes and scaffolds? (P7)

P7's final rhetorical question is interesting-leading to a realisation that building genre knowledge development into the curriculum could be advantageous, and that the model presented could be a useful tool in that process.

\section{Metacognitive awareness of how Tardy's model could be used to adapt the module/ teaching to students' needs}

Participants elaborated on how to use Tardy's model as a tool to implement changes to their own practice and improve communication with students. These comments comprised a range of adjustments: adapting the module guide (e.g. P2), the structure of the module (e.g. P9) teaching (e.g. P10) and assessment (P7). For example:

Today's session helped me realise that I have to modify significantly not only the module guide but also the module's assessment. I have to provide detailed instructions, update the key skills and upload samples of past assignments in order to support the students. (P2)

P7 gained metacognitive awareness of how to use the model to assess students' needs and refine teaching practice:

[I]n terms of adapting my practice I think this model will give me awareness of where students are struggling (or where I am not communicating clearly the types of knowledge we need to see) that will be very useful for assessment feedback and for session feedback as we go along. I think it will help me frame the assessment to students better and provide them with a better visualisation of the learning outcomes. It might also help us get them to think about where they need more guidance or where I could be more clear. (P7)

And P9 saw the potential for monitoring his teaching practice, reflecting on what changes could be implemented based on his insights:

The mapping activity was useful in helping me think about how my module is structured and how I might create better links between the introduction of new knowledge and building on existing knowledge. (P9) 
For P1, the model provided a tool to monitor his approach to teaching, as he became aware of his emphasis on subject-matter knowledge and its limitations. He plans adjustments to his practice to address the different facets of genre knowledge.

It was very useful to have a broad image of my responsibility and by having seen this it will surely be my priority to make sure I provide material to the best of my ability. Their audience certainly changes (rhetorical) therefore affecting on their formal knowledge since they need to adapt a totally new approach. Process knowledge requires a totally separate and dedicated session for our students to ensure the smooth transition or adoption of new approach. As an engineering department we are heavily focussed on subject matter knowledge. (P1)

The model served as a diagnostic tool for P15, enabling a realisation that her teaching did not address all facets of genre knowledge. She also indicated that she would adjust her practice and 'feedback' to the module leader:

I discovered that my module does not cover multiple parts of the Tardy theory [...]. I plan to feed this information back to the module leader and consider how I can better prepare the students during my lesson. (P15)

Like P15, P10 and P5 intend to discuss their new insights with other colleagues and integrate genre knowledge into their teaching, effecting change in their departments:

It is my intention to try to address this during class time by taking just a few minutes but I also want to address this with my colleagues in a broader way. (P10)

We could develop reflexive writing/self-reflection. I am going to integrate some sources into my seminars next week $[\ldots]$ and will need to embed this more in future $[\ldots]$ during the module review I will suggest we dedicate a session or two to critical reflexive writing. (P5)

In sum, these tasks promoted subject specialists' metacognitive awareness of how to use their new genre knowledge within their own context to monitor and rethink their teaching and assessment practices or initiate a broader discussion among their colleagues and students.

\section{Discussion and conclusion}

The aim of this study was twofold. First, we aimed to build subject specialists' genre knowledge, with a view to eliciting tacit knowledge about disciplinary literacy practices; second, we sought to scaffold participants' metacognitive awareness of how genre knowledge has a bearing on their pedagogical practice, specifically in relation to the assignments they set. We now briefly discuss our key findings and raise two broader points.

Task 1 helped participants to articulate their rhetorical, process and formal genre knowledge in relation to their practice. This elicitation moved the participants towards metacognitive awareness, as they reflected on their practice in the context of Tardy's model. Specifically, this task prompted recognition of the assignments' complexity and the challenges that they present for students, the hidden values and expectations that lie behind the scenes.

In terms of rhetorical knowledge, emphasis was placed on audience expectations, values of the disciplines, purposes of the genre and desirable author attributes. Under process knowledge, participants mentioned both behavioural and cognitive strategies expected. Most participants listed reading/information retrieval; however, these multi-step processes soon became 
discipline specific, which defies the appropriateness of general literacy/study skills interventions (Wingate and Tribble 2012). Reflections on formal knowledge invoked different types of literacy: academic, disciplinary, multi-modal and digital. Participants found it difficult to articulate their formal knowledge, and interwove formal features with disciplinary terminology/concepts, rhetorical aspects and even processes and purposes, which recalls the challenge of representation in eliciting tacit knowledge (Eraut 2000). These findings also explicate somewhat Lillis and Turner's (2001) study, which underscored the difficulties students have in understanding what is required in assignments - our participants were either not aware of the scope of the requirements inherent in the assignments they set, or could not articulate those requirements beyond content knowledge.

Task 3 scaffolded metacognitive awareness of the role genre knowledge plays in the participants' practice. Three main themes emerged. Comments showed gains in metacognitive awareness of participants' own expectations. These were often problematized in that a misalignment between expectations and teaching practice was noted. Furthermore, participants realised that their own assumptions about students' current knowledge/skills and prior learning, as implicitly required by the assignments they set, may be inaccurate or unreasonable. Finally, the task elicited comments that suggest participants gained metacognitive awareness of how to use Tardy's model in their own teaching as a tool to evaluate their pedagogy and adapt their practice to better meet students' needs.

Interestingly, while participants described disciplinary-specific genre knowledge, none seemed to explicitly report metacognitive awareness of academic literacy in general as situated and polylithic (e.g. Prior 1998). This reconceptualisation is necessary if attitudes toward who holds responsibility for academic literacy development at the university are to shift on a wide scale: instead of separate study skills or EAP interventions, integrated and creative approaches where subject and academic literacy specialists collaborate are required (Wingate 2016). Therefore, a potential development of our activity would be to include a final task which pushes participants towards a higher-level conceptualisation of and reflection on academic literacy (Shanahan and Shanahan 2012).

A related point is the role of academic literacy specialists. Based on our study, we encourage these specialists to work with subject specialists in a professional development role (Percy 2014), starting with an appreciation of genre and the nature of academic literacy, the turf of the academic literacy specialist. This position is not new. Johns (1997) argued that academic literacy development should be a collaborative endeavour. However, her suggestion was that EAP specialists familiarise themselves with disciplinary discourse through engagement with subject specialists to inform EAP provision (often provided separately). The significance of our study is that it highlights the value of changing the direction of this collaboration. We show how input from academic literacy specialists (with their bricolage of expertise) can impact subject specialists' practice by providing a theoretical frame and (meta)cognitive tools to evaluate and modify their teaching. As P9 commented: 'thank you for allowing us the space to think about how we teach in relation to what we expect our students to learn'. Our study underscores the importance of giving subject specialists a medium to articulate their own tacit knowledge and expectations (Eraut 2000), and as a consequence, the ability to negotiate this genre knowledge with their students.

In conclusion, the importance and originality of our study lies in the focus on the genre knowledge of the lecturer setting the assignment, rather than the student producing it, and the combination of theories from two distinct fields - metacognition and genre - to address the problem of tacit knowledge of academic literacy. Our tasks were successful in several areas. 
First, they provided a clear, easy to grasp scaffold that subject specialists from all disciplines were able to engage with and a medium to discuss rhetorical, process and formal aspects of genre knowledge. Additionally, the tasks raised metacognitive awareness of the role of academic genres in subject modules, participants' expectations, teaching practice and students' needs. Finally, for some, the tasks provided an opportunity to consider how this awareness could effect change. Our approach - with its focus on articulating implicit disciplinary genre knowledge and scaffolding a metacognitive experience - has direct application, but could also be adapted to optimise alignment in terms of expectations, teaching and assessment in HE modules. Further research could take a longitudinal perspective to track long-term impacts, such as changes to course/module design or assessment, attitudes and local collaborations. Finally, more research is needed into how subject specialists can learn to integrate the development of students' genre knowledge in their own teaching.

Funding This study was supported by the Sheffield Hallam Shaping Futures Fund.

\section{Compliance with ethical standards}

Conflict of interest The authors declare that they have no conflict of interest.

Open Access This article is distributed under the terms of the Creative Commons Attribution 4.0 International License (http://creativecommons.org/licenses/by/4.0/), which permits unrestricted use, distribution, and reproduction in any medium, provided you give appropriate credit to the original author(s) and the source, provide a link to the Creative Commons license, and indicate if changes were made.

Publisher's note Springer Nature remains neutral with regard to jurisdictional claims in published maps and institutional affiliations.

\section{References}

Berkenkotter, C., \& Huckin, T. (1995). Genre knowledge in disciplinary communication: cognition/culture/ power. Mahwah, NJ: Lawrence Erlbaum.

Brown, A. L. (1978). Knowing when, where, and how to remember: a problem of metacognition. In R. Glaser (Ed.), Advances in instructional psychology (Vol. 1, pp. 77-165). Hillsdale: Erlbaum.

Cheng, A. (2018). Genre and graduate level research writing. Ann Arbor: University of Michigan Press.

Crookes, G. (1993). Action research for second language teachers: going beyond teacher research. Applied Linguistics, 14(2), 130-144. https://doi.org/10.1093/applin/14.2.130.

van de Kamp, M. T., Admiraal, W., \& Rijlaarsdam, G. (2016). Becoming original: effects of strategy instruction. Instructional Science, 44(6), 543-566. https://doi.org/10.1007/s11251-016-9384-y.

Dinsmore, D. L., Alexander, P. A., \& Loughlin, S. M. (2008). Focusing the conceptual lens on metacognition, self-regulation, and self-regulated learning. Educational Psychology Review, 20(4), 391-409. https://doi. org/10.1007/s10648-008-9083-6.

Dysthe, O. (2002). Professors as mediators of academic text cultures. Written Communication, 19(4), 493-544. https://doi.org/10.1177/074108802238010.

Elton, L. (2010). Academic writing and tacit knowledge. Teaching in Higher Education, 15(2), 151-160. https://doi.org/10.1080/13562511003619979.

Eraut, M. (2000). Non-formal learning and tacit knowledge in professional work. British Journal of Educational Psychology, 70, 113-136.

Flavell, J. H. (1979). Metacognition and cognitive monitoring: a new area of cognitive-developmental inquiry. American Psychologist, 34(10), 906. https://doi.org/10.1037/0003-066X.34.10.906.

Haggis, T. (2006). Pedagogies for diversity: retaining critical challenge amidst fears of 'dumbing down'. Studies in Higher Education, 31(5), 521-535. https://doi.org/10.1080/03075070600922709. 
Hargrove, R. A., \& Nietfeld, J. L. (2015). The impact of metacognitive instruction on creative problem solving. The Journal of Experimental Education, 8(3), 291-318. https://doi.org/10.1080/00220973.2013.876604.

Hyland, K. (2004). Disciplinary discourses: social interactions in academic writing. University of Michigan Press.

Jenkins, J., \& Wingate, U. (2015). Staff and student perceptions of English language policies and practices in 'international' universities: a UK case study. Higher Education Review, 47(2), 47-73 ERIC: EJ1133174.

Johns, A. (1997).Text, role and context: developing academic literacies Cambridge University Press.

Johns, A. M. (2008). Genre awareness for the novice academic student: an ongoing quest. Language Teaching, 41(2), 237-252. https://doi.org/10.1017/S0261444807004892.

Krathwohl, D. R. (2002). A revision of Bloom's taxonomy: an overview. Theory Into Practice, 41(4), $212-218$. https://doi.org/10.1207/s15430421tip4104_2.

Lea, M. R., \& Street, B. V. (2006). The 'Academic Literacies' model: theory and applications. Theory Into Practice, 45(4), 368-377. https://doi.org/10.1207/s15430421tip4504_11.

Lee, I. (2013). Becoming a writing teacher: using 'identity' as an analytic lens to understand EFL writing teachers' development. Journal of Second Language Writing, 22(3), 330-345. https://doi.org/10.1016/j. jslw.2012.07.001.

Lillis, T. M., \& Turner, J. (2001). Student writing in higher education: contemporary confusion, traditional concerns. Teaching in Higher Education, 6(1), 57-68. https://doi.org/10.1080/13562510020029608.

Lincoln, Y. S., \& Guba, E. (1985). Naturalistic inquiry. Beverly Hills, CA: SAGE.

McGrath, L., \& Kaufhold, K. (2016). English for specific purposes and academic literacies: eclecticism in academic writing pedagogy. Teaching in Higher Education, 21(8), 933-947. https://doi.org/10.1080 /13562517.2016.1198762.

Metcalfe, J., \& Schwartz, B. (2016). The ghost in the machine: self-reflective consciousness and the neuroscience of metacognition. In J. Dunlosky \& S. K. Tauber (Eds), Oxford handbook of metamemory, 407-24. Oxford University Press.

Miles, M., Huberman, M., \& Saldaña, J. (2014). Qualitative data analysis. London: SAGE.

Miller, C. (1984). Genre as a social action. The Quarterly Journal of Speech, 70(2), 151-167. https://doi. org/10.1080/00335638409383686.

Negretti, R. (2017). Calibrating genre: metacognitive judgments and rhetorical effectiveness in academic writing by L2 graduate students. Applied Linguistics, 38(4), 512-539. https://doi.org/10.1093/applin/amv051.

Negretti, R., \& McGrath, L. (2018). Scaffolding genre knowledge and metacognition: insights from an L2 doctoral research writing course. Journal of Second Language Writing, 40, 12-31. https://doi.org/10.1016/j. jslw.2017.12.002.

Nelson, T. O., \& Narens, L. (1990). Metamemory: a theoretical framework and new findings. In G. H. Bower (Ed), The psychology of learning and motivation. Advances in research and theory (Vol. 26), 125-173. CA: Academic Press.

Nesi, H., \& Gardner, S. (2012). Genres across the disciplines: student writing in higher education. Cambridge: Cambridge University Press.

Paxton, M., \& Frith, V. (2014). Implications of academic literacies research for knowledge making and curriculum design. Higher Education, 67, 171-182. https://doi.org/10.1007/s10734-013-9675-z.

Percy, A. (2014). Re-integrating academic development and academic language and learning: a call to reason. Higher Education Research and Development, 33(6), 1194-1207. https://doi.org/10.1080 /07294360.2014.911254.

Pintrich, P. R. (2002). The role of metacognitive knowledge in learning, teaching, and assessing. Theory Into Practice, 41(4), 219-225. https://doi.org/10.1207/s15430421tip4104_3.

Polanyi, M. (1966). The tacit dimension. University of Chicago Press.

Prior, P. (1998). Writing/disciplinarity: a sociohistoric account of literate activity in the academy. London: Taylor Francis.

Sala-Bubaré, A., \& Castelló, M. (2017). Exploring the relationship between doctoral students' experiences and research community positioning. Studies in Continuing Education, 39(1), 16-34. https://doi.org/10.1080 /0158037X.2016.1216832.

Schraw, G., \& Dennison, R. S. (1994). Assessing metacognitive awareness. Contemporary Educational Psychology, 19, 460-475. https://doi.org/10.1006/ceps.1994.1033.

Serra, M. J., \& Metcalfe, J. (2009). Effective implementation of metacognition. In D. J. Hacker, J. Dunlosky, \& A. C. Graesser (Eds.), Handbook of metacognition in education (pp. 278-298). Mahwah, NJ: Erlbaum.

Shanahan, T., \& Shanahan, C. (2012). What is disciplinary literacy and why does it matter? Topics in Language Disorders, 32(1), 7-18. https://doi.org/10.1097/TLD.0b013e318244557a.

Swales, J. (1990). Genre analysis. Ann Arbor: University of Michigan Press.

Tardy, C. M. (2009). Building genre knowledge. West Lafayette: Parlor Press. 
Tardy, C.M., Buck, R. H., Pawlowski, M., \& Slinkard, J. R. (2018). Evolving conceptions of genre among firstyear writing teachers. Composition Forum, 38. Retrieved from http://compositionforum.com/issue/38 /evolving.php.

Wingate, U. (2016). Academic literacy across the curriculum: towards a collaborative instructional approach. Language Teaching, 1-6. https://doi.org/10.1017/S0261444816000264.

Wingate, U., \& Tribble, C. (2012). The best of both worlds? Towards an English for academic purposes/ academic literacies writing pedagogy. Studies in Higher Education, 37(4), 481-495. https://doi.org/10.1080 $/ 03075079.2010 .525630$.

Yin, R. K. (2016). Qualitative research from start to finish. New York: The Guilford Press. https://doi. org/10.1111/fcsr.12144. 